Elsevier Editorial System(tm) for International Journal of Pressure Vessels and Piping Manuscript Draft

Manuscript Number: IPVP-D-15-00001R1

Title: Leak-Before-Break : Global perspectives and procedures

Article Type: Review Article

Keywords: Leak-before-break; Fitness-for-service (FFS); Pressure vessels; Piping; Failure

Corresponding Author: Mr. Renaud Bourga,

Corresponding Author's Institution: Brunel University London

First Author: Renaud Bourga

Order of Authors: Renaud Bourga; Philippa Moore; Yin-Jin Janin; Bin Wang; John Sharples

Abstract: Structural integrity of components containing fluids is critical for economic, environmental and safety issues. Any risk of catastrophic failure, in the form of either brittle or ductile manner, is not acceptable across the industries. Consequently, many efforts have been invested in the structural integrity aspect to improve the assessment methodologies. One of the ways to aid the decision whether or not to live with the defect is through the demonstration of Leak-Before-Break (LBB). LBB which is a well-established practice in the nuclear industry, albeit as a defence-in-depth argument or to justify the elimination of pipe whip restraints, also finds its applicability in other industries. A review of the available procedures, their associated limitations and the research carried out in the last thirty years is presented in this paper. Application of this concept within non-nuclear industries is also discussed. 


\title{
Leak-Before-Break: Global perspectives and procedures
}

\author{
R. Bourga ${ }^{1}$, P. Moore ${ }^{2}$, Y-J Janin ${ }^{3}$ B. Wang ${ }^{4}, J^{\prime}$ Sharples ${ }^{5}$
}

\begin{abstract}
Structural integrity of components containing fluids is critical for economic, environmental and safety issues. Any risk of catastrophic failure, in the form of either brittle or ductile manner, is not acceptable across the industries. Consequently, many efforts have been invested in the structural integrity aspect to improve the assessment methodologies. One of the ways to aid the decision whether or not to live with the defect is through the demonstration of Leak-Before-Break (LBB). LBB which is a well-established practice in the nuclear industry, albeit as a defence-in-depth argument or to justify the elimination of pipe whip restraints, also finds its applicability in other industries. A review of the available procedures, their associated limitations and the research carried out in the last thirty years is presented in this paper. Application of this concept within non-nuclear industries is also discussed.
\end{abstract}

Keywords: Leak-before-break, Fitness-for-service (FFS), Pressure vessels, Piping, Failure

\section{Background}

Since 1950, numerous investigations have been performed to assess the mechanical and structural behaviour of pressurized components, such as loading capacity and failure behaviour of piping. One of the first few cases associated with LBB was presented by Irwin [1] in the 1960s. According to his work, leakage was predicted to occur due to an axial flaw if the defect length was less than twice the thickness of the pressure vessel. In that case, the crack driving forces in the radial direction exceed those in the axial direction resulting in a through-wall crack which could exist up to a significant size without any risks of pipe burst.

After that, most research on LBB has been carried out for nuclear applications. Historically, an instantaneous double-ended guillotine break (DEGB) of the largest heat transport pipe was used as the design basis in nuclear power plant, assuming that the pipe would break in a brittle manner [2]. This led to the installation of numerous pipe-whip restraints to hold ruptured pipes in place. However this criterion was restrictive [3], due to the risk of loose pipe ends jamming under certain conditions and the difficulties of carrying out inspection. Advances in fracture mechanics allowed a better understanding of piping behaviour and it has been demonstrated that postulated small through-wall flaws could be detected by leakage long before the flaws could grow to unstable sizes which might cause a DEGB [2]. For this reason, developing an alternate design criterion was necessary [4], [5]. Further studies have expanded the elaboration of LBB procedures, which were adopted in 1986 by the United States Nuclear Regulatory Commission (USNRC), for the assessments of high energy pipes in Pressurized Water Reactors (PWRs), which provided guidelines (revised in 2007 [6]) for safety evaluation of the operating and design of Nuclear Power Plant.

LBB assessment methods have contributed to a new approach of pressure equipment design. Details about guidance for the implementation, limitations and acceptance criteria for LBB were provided in the late 1980s by the American regulatory authority [6]-[8]. Nowadays, this criterion is widely used in the nuclear industry as either validation to remove pipe-whip restraints and jet-impingement shields or as defence-in-depth argument. Outside of the nuclear industry, LBB arguments are sometimes included as part of Fitness-for-Service (FFS) assessments.

\footnotetext{
${ }^{1}$ College of Engineering, Design and Physical Sciences, Brunel University London, Uxbridge, UB8 3PH, UK renaud.bourga@brunel.ac.uk

2 TWI Ltd, Granta Park, Great Abington, Cambridge, CB21 6AL, UK - philippa.moore@twi.co.uk

${ }^{3}$ TWI Ltd, Granta Park, Great Abington, Cambridge, CB21 6AL, UK - Yin.Jin.Janin@twi.co.uk

${ }^{4}$ College of Engineering, Design and Physical Sciences, Brunel University London, Uxbridge, UB8 3PH, UK bin.wang@brunel.ac.uk

${ }^{5}$ AMEC Foster Wheeler, Birchwood Park, Warrington, Cheshire, WA3 6GA, UK - john.sharples@amecfw.com
} 


\section{Definitions}

The European Commission [9] defines LBB as "a failure mode of a cracked piping leaking throughwall crack which may by timely and safely detected by the available monitoring systems and which does not challenge the pipe's capability to withstand any design loading". Although inelegantly described, this concept is related to pipe failures and their safety implications and it has been presented as a way to partially relax the common requirements to the postulated DEGB failure. Fracture mechanics principles are used to demonstrate that a flaw will develop through-wall allowing sufficient and stable leakage that it can be detected before catastrophic rupture of the component occurs. This concept may therefore be applied to structures containing a fluid such as pipes or pressure vessels.

LBB is applicable to ductile materials which exhibit high toughness and are fracture resistant [9]. These material properties permit a through-wall defect of a certain length to be stable under specified conditions and allow sufficient time for the detection of the resulting leak. A combination of ductile material, benign fluid environment and a reliable leak detection system is therefore necessary.

\subsection{Basic design analysis}

A basic analysis to show the balance of leak conditions and break conditions is presented in [10]. These formulations are used for the design of pressurized thin-walled structures. For example, a thinwalled cylindrical pressure vessel of radius $R$ and thickness $t$ is subject to an internal pressure $P$. In the basis of design, the maximum hoop stress cannot exceed the yield strength of the material $\left(\sigma_{\mathrm{h}} \leq \sigma_{\mathrm{ys}}\right)$, and therefore the thickness $t$ to preclude yielding has to be:

$$
t \geq \frac{P R}{\sigma_{y s}}
$$

In the case of a through-wall crack $\left(2 a_{c}=t\right)$ where a leak may be detected, the crack will remain stable if :

$$
\sigma_{h} \leq \frac{K_{I C}}{\sqrt{\pi \frac{t}{2}}}
$$

Where $\mathrm{K}_{\mathrm{IC}}$ is the plane strain fracture toughness. These two equations lead to a limiting pressure:

$$
P \leq \frac{2}{\pi R}\left(\frac{K_{I C}{ }^{2}}{\sigma_{y s}}\right)
$$

These basic conditions (more detailed procedures will be discussed in section 2.2) are used at the design stage to select materials and they may also be used to ensure that a leak-before-break condition can be feasibly reached. Design engineers select the material's yield strength and thickness according to conventional formulae of stress analysis so that the wall thickness is sufficient to withstand the internal pressure. The next step is the selection of the minimum required fracture toughness to meet the leakbefore-break criterion. This is followed by the evaluation of cost of material, fabrication, certification, and other technical and economic decisions [11].

\subsection{Detailed procedures}

In a detailed LBB assessment a number of different calculations is required, including those of the limiting length of a through wall defect and those of crack opening area. Validation of methods for the calculation of the limiting length of a through wall defect is included in the validation of flaw assessment procedures [12]. The formulation of a Leak-Before-Break argument can be explained with the aid of the following diagram (see Figure 1) where (1) and (2) represent the margins applied on leak detection and crack length and flowchart (see Figure 2). During stable crack growth (Crack length<Critical crack length) the penetrating crack will grow to a through-wall crack and form a leak until it reaches the critical length. Catastrophic failure occurs when the crack length reaches its critical length leading to unstable crack growth assuming stresses are load-controlled (generally true for pipes containing high energy fluids). Under fatigue crack growth, defects will grow under the action of cyclic stress mainly due to changes in internal pressure or due to thermal transient load cycles. For example, circumferential defects will grow under cyclic axial stresses and are subject to axial pipe end load, internal pressure and external pipe bending moments [13]. 
Typical inputs for LBB evaluation include pipe geometry, material properties, crack morphology, cyclic loads, operating pressure and temperature. The different procedures available are explained in the next part of this paper. However, having a common origin, some major steps can be summarized as follows (from [14]-[16]):

\section{i. $\quad$ Characterise/Postulate the initial flaw}

Flaw dimensions have to be defined for surface or through-wall flaws. Depending on the procedure used, surface defects may be assessed in addition to through-wall defects taking crack growth into account.

ii. Determine critical length of the through-wall flaw

This refers to the length at which the through-wall defect becomes unstable, based on fracture mechanics calculations, assuming stresses are load-controlled.

\section{iii. Estimate the flaw length at breakthrough}

This is carried out by calculating the surface flaw length at which ligament failure is predicted to occur and re-characterising this flaw as a through-wall flaw.

\section{iv. Determine detectable leakage length of the through-wall flaw}

This includes calculation of the Crack Opening Area (COA) associated with the crack length and calculation of the resulting detectable leak rate appropriate to the leak detection system capabilities. Time to detect the leak should be taken into account. The leak rate may be estimated from relevant experimental data if available or computer codes which predict leakage rates for single- or two-phase flows for a wide range of through-wall defects that appropriately account for the surface roughness, number of turns, etc for the crack mechanisms of interest.

v. Assess the results:

A case for LBB is established provided the calculations in previous steps show that:

- the flaw length at breakthrough is less than the critical length of the through-wall flaw.

- the time to detect the leak is less than the time for the flaw to grow to the critical length.

Guidance and established procedures are given in different standards and procedures to resolve each of these steps. Depending on the procedure used, different methodologies can be found with various levels of assessment and explicit margins may be given for each step. This will be further elaborated in section 3.

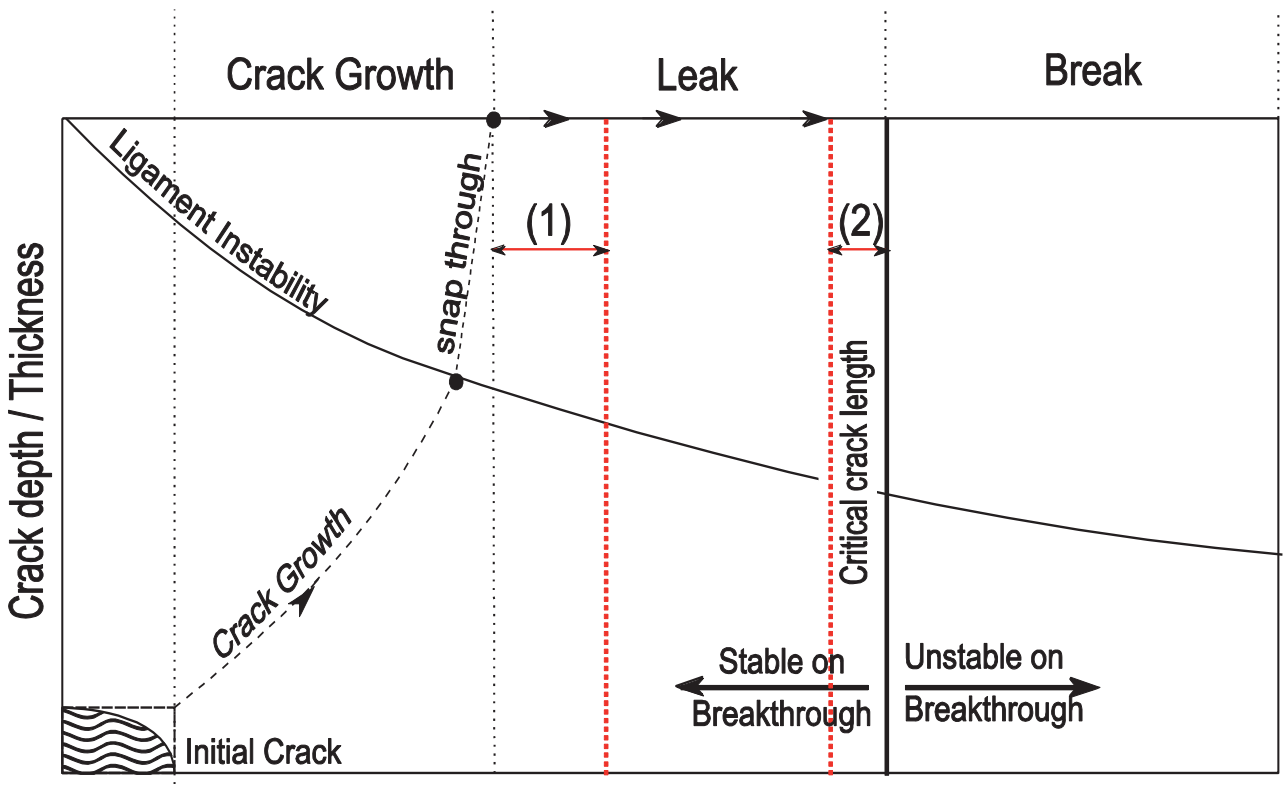

Crack length / Thickness

Figure 1: Leak-Before-Break Diagram based on [15]

(where (1) \& (2) represent margins on leak detection and crack length) 


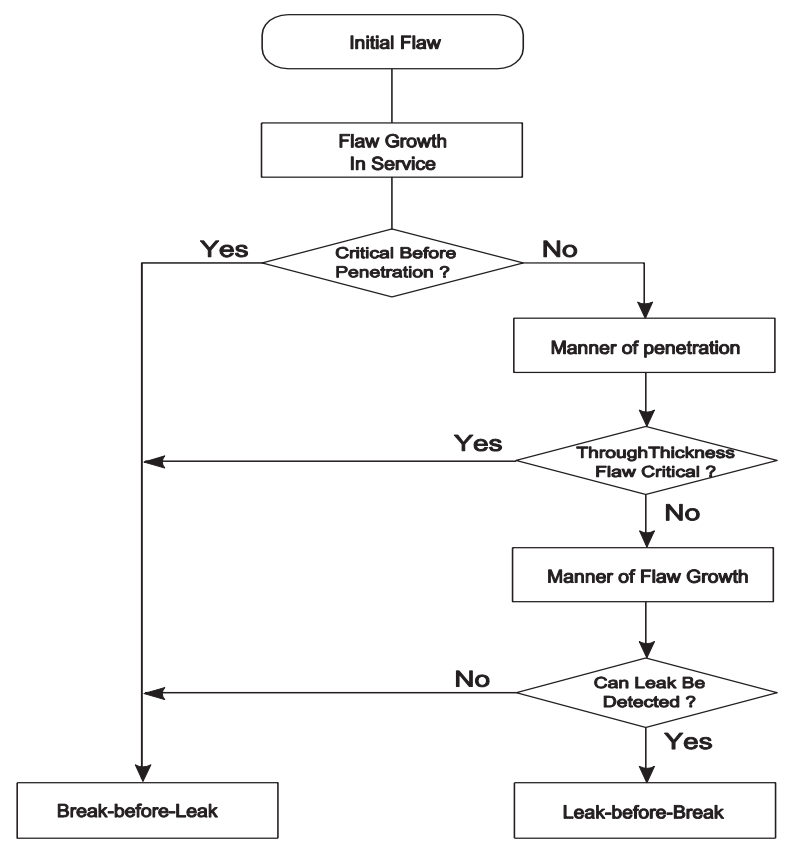

Figure 2: LBB flowchart based on [13]

\subsection{Limitations}

According to the US requirement [6], LBB methodology has to be applied to the worst location (lower material properties, higher stresses, etc.) in an entire system and should not be applied to a particular location along the pipe system alone. The initial crack may arise from different types of defect, and may grow as a result of loading or environment. However, it is generally recommended to demonstrate that certain in-service degradation mechanisms are not present: LBB is not usually applied to systems which experience excessive or unusual loads and is generally limited to piping that is not susceptible to fail from degradation mechanisms such as the following [17]:

- Water hammer

- Creep/ Creep fatigue damage

- Erosion, corrosion or erosion/corrosion

- Stress Corrosion Cracking (SCC) or Inter Granular SCC (IGSCC)

- Thermal ageing

- Brittle fracture

- Potential indirect sources of pipe rupture

Current LBB procedures only consider the case of a single crack. The scenario of multiple cracks was considered by means of Monte Carlo simulation in [18], [19]. It was concluded that this leads to a shorter leak-free time, a shorter allowable response time and that catastrophic failure may also occur without a detectable leak where a large number of initial cracks have a strong crack interaction. Therefore, a multiple crack LBB case would be analysed case by case, and in most cases would probably not be possible. In practice, many service cases of LBB occur with multiple cracks (generally due to Stress Corrosion Cracking), but how to establish the guidelines for assessment of multiple cracks is difficult.

Another significant limitation is the requirement on minimum pipe radius. In order to have sufficient margin between the leakage crack size and the critical crack size, pipe dimensions have to be appropriate. In the case of a small pipe, the critical crack length may be reached before the leak detected. In terms of pressure, LBB is generally restricted to high energy components (such as in in the nuclear industry [6] Class 1 and 2, which are the classes containing the highest pressure) in order to improve the leak detection aspect. However, it may also be applied to other significant components when defence-indepth is invoked. 


\section{Leak-Before-Break Procedures}

\subsection{Nuclear Industry}

In the last thirty years, LBB has received increased consideration as a criterion for assessing or upgrading the safety of existing plants [20] and has also been applied to optimize the design when large modifications were made. Various countries operating nuclear plant have developed their own procedures regarding $\mathrm{LBB}$ applicability taking historic and regulatory aspects into account. Two reports published by the International Atomic Energy Agency (IAEA) in 1993 and 1994 present the application of LBB in different countries [5], [21]. Other publications also provide examples of LBB applications or developments in other countries, for example France [22],[23], Belgium [24], USA [17], Canada [25], [26], Korea [27], India [28] or Czech Republic [29] where the following procedures were used with slight modifications.

According to a recent report [30], published in 2012, four distinct approaches of LBB are used throughout Europe in the nuclear industry. All these approaches share some degrees of similarities:

- Germany - Integrity Concept (IC): The LBB procedure is a part of the principle of break preclusion, now included in the overriding safety philosophy for the assessment and structural integrity maintenance of nuclear power plants [16]. The assessment itself is applied only to the most susceptible locations, such as welds, sections of increased load or material degradation. It employs the detectable leak rate to determine the crack size required for confident detection and compares this to the critical crack size. This deterministic approach and defence in depth argument renders probabilistic approaches unnecessary [9].

- USA - SRP-3.6.3 [6]: This flaw tolerance approach requires a screening criterion to be met (limitations stated earlier, Section 2.3) to ensure an incredibly low pipe break probability. Similar to other LBB procedures, the basic principle is to use the detectable leak rate to determine the crack size required for confident detection and compares this to the critical crack size to ensure suitable margins exist. LBB is only applicable to the entire section of piping, not individual components or welded joints. The LBB procedure in SRP-3.6.3 can only be applied once the reliability of the detection system has been demonstrated. The US procedure also defines margin coefficients [31]: 10 on leak detection, and either 2 on crack size or 1.4 for (normal and seismic) stresses. These margins have been defined in order to increase the degree of conservatism required in nuclear industry, and account for other uncertainties not explicitly called out in the analyses (i.e., variability of crack morphology parameters, not including cyclic effects from seismic loading on toughness, etc.). Although published in the U.S., this procedure has been adopted by some European countries [32].

- $\quad$ UK - R6 [14]: Two approaches are available. The first is a simplified 'detectable leakage approach' used in design and safety studies of a hypothetical through-wall flaw. It aims to demonstrate that a leaking flaw is detectable long before it grows to a limiting length. The second approach is a 'full LBB procedure' that considers the growth of an initial part penetrating surface flaw. In this case, it is necessary to show that the flaw penetrates the pressure boundary before it can lead to disruptive failure and that the resulting through-wall flaw leaks at a sufficient rate to ensure its detection before it grows to a limiting length at which disruptive failure occurs. Heavily based on sensitivity analyses within deterministic calculations, R6 does not apply specific safety margins. The LBB procedure in R6 can usually only be used as part of a defence in depth argument.

- France - RCC-MRX Appendix 16: Originally based on the American NUREG-1061 [7], LBB estimates are determined by comparing the crack size that allows the leak to be detected and that which causes component failure. This comparison is quantified by a safety factor of 2 on crack sizes and 10 on the detection capability. Some consideration of the crack dimensions are provided by taking into account different internal and external crack lengths.

According to [30][32], the German Integrity Concept (IC) and the American Standard Review Plan (SRP) 3.6.3 form the basic foundation of LBB assessment for most countries whereas the UK and French approaches are country-specific. Besides European and USA procedures, Japan has also developed its own procedure: 
- Japan - JSME S ND1: This guideline provides some unique features but the overall principles are consistent with those previously mentioned. Stability analysis is performed for the larger of the penetrating crack and leakage crack. Guidelines on the crack growth are given and correction of the stress intensity factor at the surface interaction has been included. A factor of 5 is applied to the leak rate and no particular safety factor is specified for the crack length or applied stresses [33].

All LBB procedures described here share the same basis and are underwritten by a large number of studies conducted in the US or Germany. However some differences are noticeable. This may be explained by the different scope of applications. While LBB has been developed in USA as a means to avoid DEGB behaviour and eliminate protections such as pipe-whip restraints and jet-impingement shields; in most European countries it has been used as a defence-in-depth argument. One important aspect to note is the difference in safety factors used. Most countries use a safety factor of 10 on leak detection and 2 on crack length (or applied stresses). Japanese guidelines recommend a factor of 5 on leak detection and 1 on crack length. In contrast, the UK procedure does not provide explicit guidance on the safety factors.

\subsection{Other industries (Non-nuclear)}

In other industries, BS 7910 and API 579 are the most comprehensive, structured and widely accepted FFS standards. They cover a broad range of equipment, and include a LBB methodology which is linked to the assessment of crack-like defects:

- API 579-1/ ASME FFS-1 (Clause 9.5.2)[34]: Guidance is given to conduct a simplified LBB assessment. Surface defects have to be re-characterized as through-wall defects. Unique CrackOpening Areas (COA) solutions are explicitly provided for both elastic and plastic conditions in cylinders and spheres.

- BS 7910 (Annex F) [15]: LBB procedures are the same than those available in R6 (Detectable leakage approach and full LBB procedure) and guidelines are given for each step. Heavily based on sensitivity analyses, no particular margins are explicitly required.

Both API 579 and BS 7910 provide a procedure for LBB analysis based on Failure Assessment Diagrams (FADs) for evaluating critical crack sizes and three levels of assessment are available. However, there are some differences with respect to parameters such as reference stress solutions and crack-opening-area solutions, both of which can lead to different results. A notable difference is the starting point of the analysis. In API 579, the starting point is a part-penetrating defect, which is then recharacterized as a through-wall defect whereas in BS 7910, depending on the procedure used, the starting point is either a through-wall defect or a part-penetrating defect (consistent with R6).

The re-characterization rules used to transform surface flaws to fully through-wall flaws also differ between API 579 and BS 7910. In BS 7910, the length of the re-characterized through-wall flaw, $2 c_{\mathrm{TW}}$, will be equal to:

$$
2 c_{T W}=2 c_{s}+t
$$

Where $2 c_{s}$ is the length of initial surface flaw and the wall-thickness. In API 579 , a more restrictive rule is used:

$$
2 c_{T W}=2 c_{s}+2 t
$$

Procedures in these standards are generally limited and the assessor is redirected to other publications or experimental work. The leakage aspect is generally less detailed than the flaw assessment due to fields of applications of these standards. For example, guidance on leak rate calculations is not explicitly provided in API 579. 


\section{Applying LBB to industries other than nuclear}

Some available publications provide illustrations where LBB has been applied outside the nuclear industry. A noticeable difference lies at the application of the concept. In the nuclear industry, procedures are strictly followed step-by-step, whereas outside the nuclear industry, each application seems to follow a hybrid procedure, taking aspects from various sources. Some examples are described below.

- A simple case study on a spherical helium storage vessel was conducted [35], where the loading was well within the yield limit of the material (301 stainless steel). LBB demonstrated that the critical depth of a surface defect was larger than the component thickness, for the crack lengths of interest.

- A LBB assessment of vertical cylindrical tanks for oil storage is provided in [36]. Investigations on crack growth are presented to show time margins between inspections. Critical defect length was calculated by means of simple fracture mechanics formulation and time-factor in terms of fatigue (with a safety factor of 20 on fatigue life).

- A large set of experiments were conducted on aluminium beverage cans (ratio of diameter to thickness up to 590) in [37]. A good correlation between plates and cans for axial crack growth was observed and the radial fracture toughness was minimum and constant for crack aspect ratios greater than 70 .

- Fitness-for-Service assessment on an ammonia storage tank in [38] used a LBB argument in order to justify an inspection plan.

- A LBB case was compared with a fatigue analysis for an offshore structure [39]. The full development and growth of a circumferential crack in a tubular member from a long deep surface crack to final failure was presented.

- The effect of pre-straining on subsea pipelines was also studied with small/full scale testing in [40] to demonstrate that a LBB case could be made since the initial assessment failed to provide sufficient margins.

- A recent published thesis looked at LBB applications on aerospace components such as high pressure fuel lines and the fuel-to-oil cooler [41].

When LBB is used outside the nuclear field, the major steps detailed in Section 2.2 are followed. However none of established procedures such as those described in Section 3.2 has strictly been followed. Various sources are used and referred to while performing assessments and this can lead to uncertainties (under- or over-estimation) on the final results. Despite such assessment procedures being readily available in general standards such as API 579 or BS 7910, the examples listed in the previous paragraph did not appear to utilise them.

It appears that there is a lack of awareness or experience with full LBB general procedures outside the nuclear industry. This might reflect a perception that they are either too complicated to apply or not sufficiently thorough. In either case, there is a need to expose both established methods more to other industries and to continue research and continuous improvements to these procedures wherever possible.

\section{$5 \quad$ Past and future research}

Over the last 30 years, a large number of research activities have been conducted in regards to LBB in the nuclear industry. Various experimental and analytical studies have been carried out on LBB behaviour of Nuclear Reactor components of non-cylindrical geometries such as tees [42], piping elbows [43], [44] and shell nozzle junctions [45], [46]. A summary of the different development and future research may be found in [32] including experiments to validate LBB using the Integrity Concept, helium environment experiments, crack shape development, crack length, crack opening area and leak rate. A selection of other research activities is discussed in the following paragraphs.

On one aspect of a LBB procedure, fracture mechanics principles are used to assess important parameters such as crack length at which the leak will be detectable and critical crack length of a throughwall crack. Finite element modelling [47], large scale plate experiments [48] and pipe experiments [49] have been conducted to assess crack shape development. Complex shaped crack analysis can also be found in [50],[51]. 
On the other aspect of the assessment, fluid mechanics and fluid-structure interactions are also important parameters in a LBB assessment. In order to detect the leak, leak rates through cracks [47]-[49] have to be evaluated to validate the leak detection system. Explicit equations for leak rates through narrow cracks (single phase flow) have been developed for four distinct flow regimes [52] using experimental work. The effect of crack morphology and surface roughness are also studied in [53][54]. It is concluded that improper morphology parameters can result in large errors in the determination of leakage crack size, leading to possible non-conservative margins. Different software codes such as DAFCAT, PICEP, SQUIRT have been developed to calculate leak rates for various crack shapes or fluids as described in [14], [31]. A recent doctorate dissertation [55] shows the effects of thermal interaction between fluid and structure for a leaking fluid. A new finite element was presented to give a convenient way to analyse this effect quickly with good accuracy [56].

The interaction between structural integrity and fluid mechanics is evident in the crack opening area (COA) parameter. Numerous models have been developed for plates, spheres and cylinders with axial and circumferential defects. Three models are available: elastic, elastic with plasticity correction [57], and elastic-plastic models [58]. High temperature effects on the rate of change of the COA have been studied with the help of 2D finite element modelling [59]. Complex geometries such as welded attachments are also taken into account [60]. Simple plate estimations can provide conservative results, which imply that detailed FE analysis may not always be required.

A large amount of work has been carried out to improve these deterministic approaches but an important effort has also been undertaken in terms of probabilistic assessments. Probabilistic assessments have been developed to strengthen deterministic assessments (i.e. ProLBB [61]) or to enlarge their applicability (i.e. xLPR (extremely Low Pipe Rupture) [62]), taking into account active degradation mechanisms, such as Primary Water Stress Corrosion Cracking (PWSCC), that are generally out of scope for a standard LBB assessment. A statistical treatment of material data, such as mechanical properties, crack resistance and fatigue crack growth curves is presented in [63]. An example of the application of a probabilistic assessment in accordance with the R6 procedure using Monte Carlo method is provided in [64]. Application of LBB in CANDU (CANada Deuterium Uranium) reactors is given in [65] or more recently in [66] to assess delayed hydride cracking.

A recent work undertaken to assess the safety aspects of Atucha II nuclear power plant piping system under beyond design basis seismic loading [67]-[68] shown surprising results. It was found important margins due to the LBB assumption that all stresses are load-controlled while the pipe system behaved more like it was displacement-controlled. The critical flaw size changed from $20 \%$ of the circumference with a traditional LBB analysis, to 95\% when the full FE model was developed, consistent with IPIRG experimental work. For circumferential flaws in a plant system, there are large margins with the established methodologies where LBB analysis are based on a load-controlled behavior compared to detailed FE models.

As far as the continuity of LBB assessment is concerned, less work is currently being undertaken and planned to be performed [32] in the near future. Present research is generally limited to the following areas:

- Extension of COA solutions for R6 (high temperature creep and constraint effects)

- Dissimilar Metal Welds application as part of an EPRI/NRC programme

- Extension on probabilistic analysis

- Application of LBB to components which are not suitable for In-Service Inspection including weld overlay

This leaves significant scope for further research to build on the existing knowledge, particularly in the areas of comparing and optimising LBB procedures, assessing the influence of welds on LBB and transition between part-penetrating and through-wall flaws. 


\section{Discussion}

LBB is widely recognised as an important methodology for supporting structural integrity safety cases in the nuclear industry. To use LBB as a fail-safe criterion, it has to be demonstrated that that any credible defect would grow through the wall in a stable way and create a detectable leak. The LBB criterion permits an extension to fracture mechanics assessment for pressurized components, by demonstrating that leakage can occur in such components for a certain time period. It is important to note that even for simple cases, LBB assessments may not be straightforward [69]. Detailed procedures are established and numerous applications as defence-in-depth or to allow the non-use of protection equipment can be found. However, performing a robust LBB assessment does not seem to be a regular practice in industries outside nuclear, despite procedures being available.

One reason for this may be that leakage of fluid through a penetrating defect will often not be tolerable, for instance, when the fluid is toxic or flammable, or its leakage has environmental consequences [70]. In the nuclear industry, processing fluids are generally water, a mix of water and air or carbon dioxide. In other industries (such as oil and gas, refinery or petrochemicals), leaking fluids are less acceptable in some circumstances due to their nature: either environmental (pollution) or safety (risk of fire or explosion) aspects cannot be accommodated with these procedures. The time-factor present in LBB procedure, which allows the crack to grow from a detectable length to a critical length, is unacceptable due to the increasing likelihood of ignition and explosion when flammable fluids leak over a period of time. However, water-based products and steam are also common fluids in refineries and these would suit LBB consideration.

Another unique feature within the nuclear industry is the confinement of the components. LBB is applied mainly on primary circuit components. In other industries, for example petrochemical and/or oil and gas, fluid-carrying components are generally in the open-air. This difference has a strong influence on the leak detection capacity, since vapour cloud detection will be affected by wind and weather conditions. Insulation of components can also increase the difficulty of leak detection.

As far as the fracture mechanics aspect is concerned, examples presented in Section 4 show that evaluations are generally limited to estimation of critical length by means of simple formulations, such as the one presented in Section 2.1. Established procedures clearly consider two aspects, namely fracture mechanics and leakage assessment and this second aspect is generally less frequently addressed.

The margins used in LBB assessments are also subject to discussion. Most of the established procedures, based on the American procedures, adopt a margin of 10 on leak detection and a margin of 2 on the crack length. However, Japanese guidelines do not apply any margins on crack length and a margin of 5 on leak detection. Some other procedures do not provide any explicit margins for LBB assessment. The higher the safety margins adopted, the more conservative the assessment will be. However it will be more difficult to satisfy LBB requirements if margins are too high. Load-controlled stresses assumption and moment reductions with the presence of large circumferential flaws also have to be considered in established LBB procedures large margins.

The main use of the LBB concept is to provide grounds for the assessment to determine the stability of penetrating defects and hence to use as a forewarning of catastrophic failure for components especially when inspection is not possible or practicable. For the assessment to remain valid the calculated leakage must be detectable and the consequences must be manageable within the context of the overall safety case. It may be useful to determine an upper bound for a part-through flaw that is growing at an unknown rate. In this case, detection of a leak will be an early warning.

It is also worth considering the solutions/treatments available. Reference stress and COA solutions are available for homogenous material. However cracks are mostly found in weldments and such effects have to be taken into account. 


\section{Conclusions}

Based on this literature study, the principal conclusions are:

- Most of the research on Leak-Before-Break has been carried out in the nuclear industry which requires a high level of safety. This industry has also developed more established procedures.

- Numerous situations and types of component have been studied and LBB is generally applied to pressurized components containing benign fluids such as water, steam and carbon dioxide.

- Only a few published applications can be found in non-nuclear industries, certainly due to the limitations discussed in section 6. However, LBB could be further developed in some areas of these industries.

- When applied to non-nuclear industries, case studies did not appear to follow established LBB procedures such as those presented in API 579 or BS 7910. A mix of different sources was generally used, which could lead to non-consistent results.

- $\quad$ The margin between the smallest detectable leak size and the critical crack size must be adequate to support LBB. Reliable leak detection methods must be employed to ensure the ultimate success of the technique in order to prevent catastrophic failure.

\section{$\underline{\text { References: }}$}

[1] G. Irwin, "Fracture of Pressure Vessels," Materials for Missiles and Spacecraft, McGraw-Hill, pp. 204-229, 1963.

[2] G. Holman, "Double-ended breaks in reactor primary piping," Nuclear Engineering and Design, vol. 89, no. 1, pp. 1-12, Nov. 1985.

[3] USNRC, "Safety evaluation of Westinghouse topical reports dealing with the elimination of postulated pipe breaks in PWR primary main loop (Generic Letter 84-04)," 1984.

[4] USNRC, State-of-the-Art Report on Piping Fracture Mechanics. NUREG/CR-6540, 1998.

[5] IAEA, Applicability of the Leak-Before-Break Concept. Vienna: International Atomic Energy Agency, IAEA-TECDOC-710, 1993.

[6] USNRC, Standard Review Plan 3.6.3 Rev.1 - Leak-Before-Break Evaluation Procedures, no. 301. NUREG-0800, 2007.

[7] USNRC, Report of the U.S. Nuclear Regulatory Commission Piping Review Committee Evaluation of Potential for Pipe Breaks. NUREG-1061, Vol.3, 1984.

[8] USNRC, NRC Leak-Before-Break (LBB.NRC) Analysis Method for Circumferentially Through-Wall Cracked Pipes Under Axial Plus Bending Loads. NUREG/CR-4572, 1986.

[9] European Commission, European Safety Practices on the application of Leak Before Break (LBB) concept. Report EUR18549 EN, 2000.

[10] S. Chattopadhyay, "Material Selection for a Pressure Vessel," in Materials in Design and Manufacturing, Annual Conference \& Exposition, ASEE, 2008.

[11] A. Blake, Practical Fracture Mechanics in Design. CRC Press, 1996.

[12] U. Zerbst and R. Ainsworth, "Experiences with some European flaw assessment procedures," in Proceedings of the 11th International Congress on Fracture, 2005.

[13] B. Darlaston, "Some aspects of leak before break; their quantification and application," Nuclear Engineering and Design, vol. 84, no. 2, pp. 225-232, Jan. 1985.

[14] R6 - Assessment of the integrity of structures containing defects. CEGB Document No. R/H/R6Rev. 4, Central Electricity Generating Board.

[15] BS 7910:2013 - Guide to methods for assessing the acceptability of flaws in metallic structures. London: British Standards Institution (BSI).

[16] D. Rieck and R. Wernicke, "Experiences with fracture mechanics Leak-Before-Break evaluations within the German Integrity Concept for NPPs," in Proceedings of the 18th European Conference on Fracture, 2010.

[17] B. Beaudoin, D. Quiñones, and T. Hardin, "Leak-before-break application in US light water reactor balance-of-plant piping," International Journal of Pressure Vessels and Piping, vol. 43, no. 1-3, pp. 67-83, Jan. 1990. 
[18] L. Xie, "The effect of characteristic crack sizes on the leak-before-break case of pressure vessels and piping with multiple cracks," International Journal of Pressure Vessels and Piping, vol. 76, no. 7, pp. 435-439, Jun. 1999.

[19] L. Xie, "Multi-crack growth/coalescence simulation and its role in passive component leak-beforebreak concept," Nuclear Engineering and Design, vol. 194, no. 2-3, pp. 113-122, Dec. 1999.

[20] European Commission, 30 Years of NRWG activities towards harmonization of nuclear safety criteria and requirements. Report EUR20818 EN, 2002.

[21] IAEA, Guidance for the application of the Leak-Before-Break Concept. Vienna: International Atomic Energy Agency, IAEA-TECDOC-774, 1994.

[22] C. Faidy, "Leak before break application in French PWR plants under operation," in Proceedings of the seminar on leak before break in reactor piping and vessels, 1995, pp. 145-150.

[23] C. Faidy, S. Bhandari, and P. Jamet, "Leak-before-break in French nuclear power plants," International Journal of Pressure Vessels and Piping, vol. 43, no. 1-3, pp. 151-163, Jan. 1990.

[24] R. Gerard, C. Malekian, and O. Meessen, "Belgian experience in applying the 'leak-before-break' concept to the primary loop piping," in Proceedings of the seminar on leak before break in reactor piping and vessels, 1995, pp. 137-144.

[25] M. Aggarwal, M. Kozluk, T. Lin, B. Manning, and D. Vijay, "A leak-before-break strategy for CANDU primary piping systems," International Journal of Pressure Vessels and Piping, vol. 25, no. 1-4, pp. 239-256, Jan. 1986.

[26] J. Nathwani and J. Stebbing, “Ontario hydro's leak-before-break approach to Darlington NGS heat transport system piping," International Journal of Pressure Vessels and Piping, vol. 43, no. 1-3, pp. 113-127, Jan. 1990.

[27] Y. Park and Y. Chung, "Leak-before-break assessment of CANDU pressure tube considering leak detection capability," Nuclear Engineering and Design, vol. 191, no. 2, pp. 205-216, Jul. 1999.

[28] J. Chattopadhyay, B. Dutta, and H. Kushwaha, "Leak-before-break qualification of primary heat transport piping of 500MWe Tarapur atomic power plant," International Journal of Pressure Vessels and Piping, vol. 76, no. 4, pp. 221-243, Apr. 1999.

[29] J. Zdarek, L. Pecinka, and P. Kadecka, "Leak-before-break criterion applied to VVER 440/230 unit," Theoretical and Applied Fracture Mechanics, vol. 23, no. 2, pp. 117-123, Jul. 1995.

[30] E. Keim and D. Lidbury, Review of assessment methods used in nuclear plant life management. (Available at http://www.vtt.fi/proj/nulife/nulife_d1_d2_report_master_11may2012.pdf), 2012.

[31] USNRC, Development of Technical Basis for Leak-Before-Break Evaluation Procedures. NUREG/CR-6765, 2002.

[32] J. Sharples, "STYLE: Comparison of Leak-Before-Break Methodologies Applied in Europe," in Proceedings of the ASME 2012 Pressure Vessels \& Piping Conference, 2012, pp. 763-768.

[33] Y. Takahashi, "Leak-Before-Break Assessment in JSME Standard," in ASME 2011 Pressure Vessels and Piping Conference, 2011, pp. 147-151.

[34] "API 579-1/ASME FFS-1 2007 Fitness-For-Service." American Society of Mechanical Engineers, New York, USA, 2007.

[35] N. Drozdziel, "Leak-before-break characterization and demonstration of a high-pressurant helium storage vessel," in Proceedings of the 5th International Congress on Fracture, 1981, pp. 21452151.

[36] V. Knysh, A. Barvinko, Y. Barvinko, and A. Yashnik, "Substantiation of «Leak-before-Break» criterion for vertical cylindrical tanks for oil storage," The Paton Welding Journal, vol. \#9, pp. 2629, 2012.

[37] M. Hackworth and J. Henshaw, "A pressure vessel fracture mechanics study of the aluminum beverage can," Engineering Fracture Mechanics, vol. 65, no. 5, pp. 525-539, Mar. 2000.

[38] M. Walter and R. Lesicki, "Measures taken to ensure safe operation of an ammonia storage tank," Process Safety Progress, vol. 17, no. 4, pp. 288-296, Jan. 1998.

[39] K. Kou and F. Burdekin, "The applicability of leak-before-break on flooded member detection for offshore structures under fatigue," Engineering Fracture Mechanics, vol. 75, no. 1, pp. 31-40, Jan. 2008.

[40] R. Andrews, N. Millwood, S. Tiku, N. Pussegoda, M. Hoekstra, and S. Smith, "Analysis and Testing of a $13 \mathrm{Cr}$ Pipeline to Demonstrate 'Leak Before Break,"' in Proceedings of the 9th International Pipeline Conference, 2012, pp. 83-91. 
[41] C. Bonn, "Estimation of Crack Opening Displacement and Leak Rates Through a Through-Flaw in Aerospace Pressure Vessels," Master Thesis, Rensselaer Polytechnic Institute, 2008.

[42] P. Chellapandi, R. Srinivasan, A. Biswas, S. Chetal, and S. Bhoje, "Leak Before Break Investigation on Sodium Piping for Prototype Fast Breeder Reactor," in Transactions of the 17th International Conference on Structural Mechanics in Reactor Technology (SMiRT 17), 2003.

[43] P. Nagapadmaja, V. Kalyanaraman, S. Satish Kumar, and P. Chellapandi, "Experimental study on LBB behaviour of LMFBR pipe elbows," International Journal of Fatigue, vol. 30, no. 3, pp. 574584, Mar. 2008.

[44] S. Bhandari, M. Fortmann, L. Grueter, J. Heliot, P. Meyer, B. Percie Du Sert, A. Prado, and H. Zeibig, "Crack propagation in a LMFBR elbow," Nuclear Engineering and Design, vol. 91, no. 2, pp. 107-119, Jan. 1986.

[45] N. Mani, G. Thanigaiyarasu, and P. Chellapandi, "Static stress analysis of steam generator shell nozzle junction for leak before break analysis," International Journal on Design and Manufacturing Technologies, vol. 3, no. 1, pp. 45-50, 2009.

[46] V. Ukadgaonker, Y. Khairnar, P. Vaidya, and P. Chellapandi, "Leak-before-break analysis of shellnozzle junction of steam generator," Indian Journal of Engineering \& Materials Sciences, vol. 9, pp. 237-249, 2002.

[47] S. Burande and R. Sethuraman, "Computational simulation of fatigue crack growth and demonstration of leak before break criterion," International Journal of Pressure Vessels and Piping, vol. 76, no. 5, pp. 331-338, Apr. 1999.

[48] B. Brickstad and I. Sattari-Far, "Crack shape developments for LBB applications," Engineering Fracture Mechanics, vol. 67, no. 6, pp. 625-646, Dec. 2000.

[49] E. Roos, K. Herter, P. Julisch, G. Bartholomé, and G. Senski, "Assessment of large scale pipe tests by fracture mechanics approximation procedures with regard to leak-before-break," Nuclear Engineering and Design, vol. 112, pp. 183-195, Mar. 1989.

[50] R. Lukess, "Predicting the Crack Response for a Pipe with a Complex Crack," PhD Thesis, University of South Carolina, 2013.

[51] S. Yellowlees, K. Lynch, A. Warren, J. Sharples, and P. Budden, "Development of Guidance for Leak-Before-Break Analysis for Complex Shaped Cracks," in ASME 2005 Pressure Vessels and Piping Conference, 2005, vol. 2005, pp. 361-370.

[52] S. Beck, N. Bagshaw, and J. Yates, "Explicit equations for leak rates through narrow cracks," International Journal of Pressure Vessels and Piping, vol. 82, no. 7, pp. 565-570, Jul. 2005.

[53] D. Rudland, G. Wilkowski, and P. Scott, "Effects of crack morphology parameters on leak-rate calculations in LBB evaluations," International Journal of Pressure Vessels and Piping, vol. 79, no. 2, pp. 99-102, Feb. 2002.

[54] T. Chivers, "The influence of surface roughness on fluid flow through cracks," Fatigue \& Fracture of Engineering Materials \& Structures, vol. 25, no. 11, pp. 1095-1102, 2002.

[55] P. Gill, "Investigating leak rates for 'leak-before-break' assessments," EngD Thesis, University of Manchester, 2013.

[56] P. Gill and K. Davey, "A thermomechanical finite element tool for Leak-before-Break analysis," International Journal for Numerical Methods in Engineering, vol. 98, no. 9, pp. 678-702, 2014.

[57] C. Wüthrich, "Crack opening areas in pressure vessels and pipes," Engineering Fracture Mechanics, vol. 18, no. 5, pp. 1049-1057, Jan. 1983.

[58] Y. Takahashi, Comprehensive Structural Integrity. Elsevier, 2003, pp. 427-464.

[59] S. Yellowlees, D. Hooton, J. Sharples, P. Budden, and D. Dean, "Crack Opening Areas During High Temperature Operation," in ASME 2002 Pressure Vessels and Piping Conference, 2002, vol. 2002, pp. 25-31.

[60] J. Sharples, C. Madew, R. Charles, and P. Budden, "Further Studies to Evaluate Crack Opening Areas for Through-Wall Cracks in the Vicinity of Welded Attachments," in ASME 2010 Pressure Vessels and Piping Conference, 2010, pp. 733-739.

[61] P. Dillström and W. Zang, "ProLBB - A Probabilistic Approach to Leak Before Break Demonstration." SKI Report 2007:43.

[62] "xLPR Pilot Study Report." U.S.NRC-RES, Washington, DC, and EPRI, Palo Alto, CA: NUREG2110 and EPRI 1022860. 2012. 
[63] I. Varfolomeev, D. Ivanov, D. Siegele, and G. Nagel, "Probabilistic Leak-Before-Break Assessment of a Main Coolant Line," in ASME 2010 Pressure Vessels and Piping Conference, 2010, pp. 371378.

[64] D. W. Beardsmore, S. F. Yellowlees, J. K. Sharples, R. A. Ainsworth, and P. J. Budden, "A Probabilistic Application of the R6 Detectable Leakage Leak-Before-Break Procedure," in ASME 2002 Pressure Vessels and Piping Conference, 2002, vol. 2002, pp. 97-104.

[65] M. Puls, B. Wilkins, G. Rigby, J. Mistry, and P. Sedran, "A probabilistic method for leak-beforebreak analysis of CANDU reactor pressure tubes," Nuclear Engineering and Design, vol. 185, no. 2-3, pp. 241-248, Oct. 1998.

[66] Y.-J. Oh and Y.-S. Chang, "Integrated probabilistic assessment for DHC initiation, growth and leakbefore-break of PHWR pressure tubes," Nuclear Engineering and Design, vol. 275, pp. 30-43, Aug. 2014.

[67] G. Wilkowski, B. Brust et al., "Robust LBB Analyses for Atucha II Nuclear Plant," in ASME 2011 Pressure Vessels \& Piping Division Conference, 2011, pp. 107-120.

[68] T. Zhang, F. Brust, G. Wilkowski, H. Xu, A. Betervide, and O. Mazzantini, "Beyond Design Basis Seismic Analysis for Atucha II Nuclear Plant," in 20th International Conference on Nuclear Engineering, 2012, pp. 625-634.

[69] P. Bouchard, "Practical applications of the R6 Leak-before-Break procedure," in Proceedings of the seminar on leak before break in reactor piping and vessels, 1995, pp. 127-136.

[70] M. Sam Mannan, The 100 Largest Losses (in the Hydrocarbon Industry) 1974-2013. (Available at : https://uk.marsh.com/Portals/18/Documents/100_Largest_Losses_23rd_Edition_2014.pdf), 2014. 